\title{
CORRECTION
}

\section{Correction to: Timing of treatment of aneurysmal subarachnoid haemorrhage: are the goals set in international guidelines achievable?}

\author{
Abdurehman Choudhry ${ }^{1,3} \cdot$ Daniel Murray ${ }^{1} \cdot$ Paula Corr $^{1} \cdot$ Deirdre Nolan $^{1} \cdot$ Deirdre Coffey $^{1} \cdot$ Stephen MacNally $^{1}$. \\ Alan O'Hare ${ }^{2}$. Sarah Power ${ }^{2}$. Matthew Crockett ${ }^{2}$. John Thornton ${ }^{2,3} \cdot$ Daniel Rawluk ${ }^{1} \cdot$ Paul Brennan $^{2,3}$. \\ Mohsen Javadpour ${ }^{1,3,4}$
}

Published online: 8 March 2021

(c) Royal Academy of Medicine in Ireland 2021

\section{Correction to: Irish Journal of Medical Science (2021) https://doi.org/10.1007/s11845-021-02542-1}

The original article contains an error. In Table 5, 'h' was missing and should be corrected to " $<48 \mathrm{~h}$ ". The correct Table is presented here.

The original article has been corrected.

[see original article for the Table layout]

Table 5 Proportion of patients treated within $48 \mathrm{~h}$ of ictus in subgroups referred within or later than $24 \mathrm{~h}$ after ictus

\begin{tabular}{llllll}
\hline WFNS Grade & \multicolumn{2}{l}{ Ictus to referral $(<24 \mathrm{~h})$} & & \multicolumn{2}{l}{ Ictus to referral $(>24 \mathrm{~h})$} \\
\cline { 2 - 3 } & $\begin{array}{l}\text { Number of } \\
\text { patients }\end{array}$ & Ictus to Tx $(<48 \mathrm{~h})$ & & $\begin{array}{l}\text { Number of } \\
\text { patients }\end{array}$ & Ictus to Tx $(<48 \mathrm{~h})$ \\
\hline WFNS grades 1-3 & 331 & $301(90.94 \%)$ & & 91 & $2(2.20 \%)$ \\
WFNS grades 4-5 & 113 & $94(83.19 \%)$ & & 3 & $1(33.33 \%)$ \\
Total & 444 & $395(88.96 \%)$ & & 94 & $3(3.19 \%)$ \\
\hline
\end{tabular}

The original article can be found online at https://doi.org/10.1007/ s11845-021-02542-1

Mohsen Javadpour

mjavadpour@rcsi.ie

1 National Neurosurgical Centre, Beaumont Hospital, Dublin, Ireland

2 Department of Neuroradiology, Beaumont Hospital, Dublin, Ireland

3 Royal College of Surgeons in Ireland, Dublin, Ireland

4 Trinity College Dublin, Dublin, Ireland 